\section{Maternal death due to domestic violence: an unrecognized critical component of maternal mortality}

\author{
Henry Espinoza ${ }^{1}$ \\ and Alma Virginia Camacho
}

Key words: battered women, domestic violence, maternal mortality, pregnancy complications, population surveillance, data collection.

\footnotetext{
1 Pan American Health Organization, Gender, Ethnicity, and Health Unit, Training Program in International Health, Washington, D.C., United States of America.

2 Pan American Health Organization, Family and Community Health, Women and Maternal Health Unit, Maternal Mortality Regional Initiative, Washington, D.C. 20037, United States of America. Send correspondence to: A. Virginia Camacho, Pan American Health Organization, 525 23rd Street, N.W., Washington, D.C. 20037, United States of America; telephone: (202) 974-3000; e-mail: camachov@paho.org
}

The last two decades have seen progress in the comprehension of and approaches to both domestic violence and maternal mortality. Governments' commitments to women's initiatives at the international and national level, such as the Convention on the Elimination of All Forms of Discrimination against Women and the Safe Motherhood Initiative, are testimonies to this progress. The Beijing Platform for Action, adopted in 1995 by most countries, is a strong model of a direct call for governments to generate statistics on and make appropriate responses to the consequences of violence against women (1).

High rates of domestic violence and disproportionately high maternal mortality ratios in developing countries are recognized as global public health problems. (The maternal mortality ratio is a measure of the risk of death of women when pregnant. It is usually measured in terms of maternal deaths per 100000 live births.) Domestic violence and maternal mortality are linked because some women die from domestic violence while pregnant or during the period following the end of pregnancy. However, it is not yet known what proportion of maternal mortality is due to domestic violence, whether there are differences between countries in that proportion, and what factors could explain any such differences. It may be challenging to generate data on the concurrence of domestic violence and maternal mortality, but such information could be used to develop a joint strategic framework on safe motherhood and on gender health that comprehensively addresses this issue. Acting now against domestic violence is essential for all pregnant women, whether their childbearing is desired or not.

A definition of "maternal death due to domestic violence" should take into account several components, including violent death, violence against women, and the current international definition of maternal death. There are various questions that need to be answered when working out the definition of maternal death due to domestic violence. These questions include: Which maternal deaths are caused by domestic violence? Would it only be deaths caused by direct lethal trauma, or should deaths due to obstetric complications that are initially caused by physical injuries also be included (for example, a placental abruption secondary to an abdominal trauma)? Can psychological violence be included as a cause of maternal death? Would these 
deaths refer only to domestic violence by the intimate partner? And, should the motives of violence be considered as part of the definition as well?

The purpose of this piece is to examine some of these components in order to stress the need to work on a more inclusive definition of maternal mortality that considers domestic violence as a cause of death. Reaching a consensus on such a definition will be a major step for the international community. However, country officials will still be left with the responsibility of collecting, processing, and analyzing data, and of making recommendations. Therefore, in this piece we will also discuss some ideas that we hope will help country officials to better handle these tasks.

\section{DEATHS DUE TO VIOLENCE}

Deaths due to violence in general or due to violent mechanisms are more properly referred to as deaths due to external causes of injury $(2,3)$. Death due to violence can be accidental or intentional. Intentional death includes self-infliction (suicide) or infliction by someone else (homicide) (4). Femicide is a term frequently used to designate the murder of a woman by her intimate partner $(5,6)$.

Intimate partners are the most frequent assailants of women. For example, an evaluation of the Caribbean conducted by the Economic Commission for Latin America and the Caribbean showed that femicides constituted almost half of all reported homicides in the Bahamas in 2002 (6). The same evaluation indicated that half of the cases of murdered women in Trinidad and Tobago in 1996 were indeed femicides.

In most developed countries, pregnancyrelated suicide is rare (7). This is most likely due to supportive legislation and health services, particularly for a woman facing an unwanted pregnancy. In contrast, in most developing countries, services to prevent and deal with unwanted pregnancies and unsafe abortion are very limited. With fewer options and probably less protection, a woman continuing with an unwanted pregnancy in a developing country may be at greater risk of committing suicide or of being killed by her intimate partner.

Studies on the issue of homicide or suicide due to unwanted pregnancy, however, are scant. A report from a special surveillance project in Bangladesh showed that for the 1976-1993 period, pregnant teenagers were at higher risk of dying from suicide and homicide than both their nonpregnant peers and older pregnant women (4). The authors suggested that unwanted pregnancies might have been an important factor for the increased risk. A study from Africa, conducted in the late 1990s, suggested that some maternal deaths could be largely due to social stigma towards unwanted pregnancy or abortion (8). In the social context investigated, some young women preferred to die rather than reveal that they were pregnant. A study conducted in the Mexican state of Morelos found that violent deaths of women associated with unwanted pregnancy might have contributed to $15 \%$ of maternal mortality (9). Half of these deaths were adolescents who committed suicide after realizing they were facing an undesired pregnancy.

\section{VIOLENCE AGAINST WOMEN, INCLUDING DURING PREGNANCY}

Domestic violence against women refers to all gender-based violent acts perpetrated against women, including physical, sexual, and psychological violence that occurs within the family (10). A more complete definition of violence against women is given in the United Nations Declaration on the Elimination of Violence against Women (10):

"Any act of gender-based violence that results in, or is likely to result in, physical, sexual or psychological harm or suffering to women, including threats of such acts, coercion or arbitrary deprivation of liberty, whether occurring in public or private life. Note: It encompasses, but is not limited to, physical, sexual and psychological violence occurring in the family, including battering, sexual abuse of female children in the household, dowry related violence, marital rape, female genital mutilation and other traditional practices harmful to women; non-spousal violence and violence related to exploitation; physical, sexual and psychological violence occurring within the general community, including rape, sexual abuse, sexual harassment and intimidation at work, in educational institutions and elsewhere; trafficking in women and forced prostitution; and physical, sexual and psychological violence perpetrated or condoned by the state, wherever it occurs."

Domestic violence is a type of gender-based violence that occurs within the social context of women's subordination and their familial bonds. Research from both developed and developing countries has shown domestic violence to be very common. For instance, population surveys from at least 36 countries found that between $10 \%$ and $69 \%$ of the women interviewed reported that a former or current intimate partner had physically attacked them at least once (11). In terms of violence during 
pregnancy there is less information available, particularly from developing countries. However, evidence shows that violence during pregnancy is also common, and that the issue of unwanted pregnancy may play a role.

In a representative survey of reproductiveaged women in Nicaragua, researchers found a higher frequency of intimate-partner violence during pregnancy (12). In the United States of America, women with unwanted pregnancies were four times as likely to experience intimate-partner violence as were women with wanted pregnancies (13).

\section{THE DEFINITION OF MATERNAL DEATH AND ITS LIMITATIONS WITH REGARD TO DOMESTIC VIOLENCE}

The main problem in estimating the contribution of domestic violence to the maternal mortality ratio rests in the current international definition of maternal death used by most countries. This definition does not consider incidental or accidental causes of death, and thus excludes deaths from domestic violence from the numerator of the maternal mortality ratio formula. There are studies that have highlighted the existence of maternal deaths due to domestic violence. They have done so, however, without greater discussion of the definition used and the implications of such a definition in measurements of maternal mortality $(7,14)$. We authors believe that there is a need for additional research and reflection on the eventual programmatic implications of this issue.

To generate, code, and estimate maternal mortality figures, most countries in the world use the current definition of maternal death and two other, related definitions established in the tenth revision of the International Classification of Diseases (ICD10). These definitions are "maternal death" (with its subdivision of direct and indirect obstetric death causes), "late maternal death," and "pregnancyrelated death."

A maternal death is "the death of a woman while pregnant or within 42 days of termination of pregnancy, regardless of the duration and site of the pregnancy, from any cause related to or aggravated by the pregnancy or its management, but not from accidental or incidental causes" (3). The death is considered as due to a direct obstetric cause when it results from complications of the pregnancy state (pregnancy, delivery, and postpartum). The death is considered as due to an indirect obstetric cause when the pregnancy triggers or aggravates a medical condition or preexisting disease.

Late maternal deaths are caused by both direct and indirect causes, and they take place at any time more than 42 days but less than one year after the termination of the pregnancy.

If all deaths from accidental or incidental causes are added to those as defined by "maternal death," the term is designated as "pregnancyrelated death" (3).

The definitions of "maternal death" and "late maternal death" primarily try to capture all deaths that are likely to occur under conditions closely related to being pregnant. A maternal death due to domestic violence is not in or within the ICD-10 definitions. Therefore, without having appropriate terminology and definitions, current information systems cannot accurately count this type of death.

Aside from these three worldwide working definitions, there are two additional ones that are used only in the United States by the Centers for Diseases Control and Prevention (CDC): "pregnancyassociated death" and "pregnancy-related death" (15). The CDC "pregnancy-associated death" definition corresponds to the ICD-10 "pregnancyrelated death" definition, but the CDC "pregnancyassociated death" definition has two periods of observations: one within 42 days after the end of pregnancy, and the other between 43 and 365 days after pregnancy termination. The "pregnancyrelated death" definition of the CDC does not have an equivalent in ICD-10 definitions. In any case, while the CDC definitions do allow the surveillance system in the United States to more completely identify all deaths related to pregnancy, these definitions do not specify what a maternal death due to domestic violence is, nor can the information system count this type of death.

Maternal mortality surveillance systems have provided inputs to enhance national statistical reports, and now most countries know what their leading causes of maternal death are. Maternal deaths are mainly due to direct obstetric causes (16) (e.g., hemorrhages, toxemia, infections, and unsafe abortion). However, it is clear that these are the causes that are most frequently measured. Correspondingly, health agencies have been called on to emphasize increasing access to care for obstetrical complications (17). Nonetheless, the importance and usefulness of the maternal mortality ratio is well known. Most countries use this indicator as a measurement of progress in terms of social development, the state of health services and systems, the health status of women, and even as a measure of social justice (since the majority of maternal deaths are concentrated among the poorest communities) (16).

In most developed countries, maternal mortality is very low. However, deaths of pregnant women due to violence do occur, and abused pregnant women may be more likely to be murdered 
than nonabused ones. Researchers have found in some areas of the United States that among pregnant women, deaths due to external causes of injury (including homicides) are more frequent than are deaths due to any other specific medical condition (18). Another study found that for women abused during pregnancy the risk of being murdered or suffering an attempted murder was three times as high as it was for nonabused pregnant women (5). Data such as these indicate the need to develop a more inclusive definition of maternal mortality, including allowing for the assessment of the contribution of domestic violence.

We believe that maternal mortality measurement is not sufficiently gender-sensitive. That is because the formula for the maternal mortality ratio was not originally created to take into account deaths of pregnant women due to gender-based violence. However, the ratio could be modified to consider those deaths. Generating accurate data on maternal deaths due to domestic violence would require the public health community to discuss the conceptual framework for data collection and management, the logistical needs for making it possible for information and surveillance systems to process the data, and, most importantly, the policy implications of data interpretation that would allow the development of appropriate interventions.

\section{DOMESTIC VIOLENCE AS A CAUSE OF MATERNAL DEATH}

Domestic violence as a health problem or as a condition of ill health does not correspond to a physiopathological definition of disease. Consequently, "domestic violence" is not specified in ICD-10. Domestic violence is essentially a behavioral problem, as are alcoholism and drug consumption. ICD-10 does make it possible to code and attribute mortality for alcoholism as a behavioral ailment (codes F10.2, F10.3), but it does not do the same for domestic violence (3). ICD-10 does provide codes for deaths due to several types of abuse and to specific perpetrators under the category of external causes of injury (codes Y06, Y07), which may make it possible to identify a limited number of deaths due to domestic violence.

To establish a cause of death there have to be clear mechanisms of causation. In the case of domestic violence, Peterson et al. (19) explain that the death of a pregnant woman can be produced through the mechanisms of direct trauma and stress, both of which can lead to deadly complications for the woman and her fetus.

In debating whether a maternal death due to domestic violence should be counted as an indirect obstetric cause, it is important to first discuss why most deaths of pregnant women due to, for example, diabetes mellitus or chronic hypertension are classified as being due to indirect obstetric causes. These diseases can start during pregnancy or can be aggravated by the pregnancy. If a pregnant woman dies due to these diseases, it is often assumed that obstetrical care would not have prevented her death. Actual avoidance of this fatality would have been possible only if the woman had never gotten pregnant. So, how much different is the reasoning in these cases from the reasoning with deaths due to domestic violence? Domestic violence can also begin during or be aggravated by pregnancy (20), as happens with many diseases. More data are needed to explain whether changes in the patterns of violence (e.g., the type of violence or its frequency) are closely related to the pregnancy stage and to whether the pregnancy was wanted or not. However, some reported cases of murder associated with the existence of a pregnancy highlight the fact that this issue deserves more discussion. For example, in a homicide involving "honor killing," a woman is murdered to repair or prevent the "damage" that her pregnancy could cause to the reputation of her partner or family (21). In such a case, avoidance of the death would have been possible only by preventing the pregnancy. Consequently, if it were possible to establish that domestic violence and a death during pregnancy were causally related (and this could be in the strict sense that the killing was motivated by the pregnancy), shouldn't this maternal death be counted as being due to domestic violence? This consideration would probably not apply to other forms of violent death, or to death due to injuries such as snakebites or accidents in general. The intention to commit genderbased violence toward the woman and her pregnancy is unlikely to exist in accidents per se. Therefore, for most cases of maternal death that are possibly due to domestic violence, it is important to consider the specific circumstances of each case. This is what maternal mortality committees generally do for each maternal death that takes place in a health institution.

\section{DATA COLLECTION}

Maternal mortality has been the subject of epidemiological surveillance for several decades, especially in developed countries. Problems with underreporting and misclassification persist, but they have stimulated the development of new techniques to estimate maternal mortality ratios, thus facilitating comparisons of patterns and trends among countries and regions (22). At present, despite the growing global interest in measuring vio- 
lent deaths of pregnant women, neither the official figures (usually produced by a country's surveillance system) nor the adjusted estimates of maternal mortality (such as those developed by the World Health Organization) reflect the impact of domestic violence on maternal mortality.

Expanding the definition of maternal death to include death due to domestic violence as a direct or indirect obstetric cause (and making the subsequent adjustment in the maternal mortality ratio) would pose challenges in identifying, registering, and reporting this type of death. Initial efforts to develop and strengthen the maternal mortality surveillance systems in Latin America and the Caribbean have already provided information that is allowing the identification of maternal deaths due to violence in general and gender-based violence in particular. For example, in Nicaragua the maternal mortality surveillance system is able to identify maternal deaths that are clearly associated with violence, but the information system only captures about $60 \%$ of the total mortality in the country.

The information systems in many of the countries of the Region of the Americas are not fully developed. Even countries, such as Mexico, that have systems with much broader coverage are working to improve data quality by addressing problems with data management, misclassification, and/or underreporting. The surveillance cycle is an ongoing process of identifying cases, collecting data, analyzing the data, recommending actions, evaluating outcomes, and refining recommendations (23). Understanding surveillance as a cycle increases the possibilities for continuous improvement in the information system. Having high-quality information from a high-quality surveillance system enables managers, policymakers, and health care providers at various levels of the health system not only to identify deaths and to collect and analyze data, but also to strengthen the decision-making process so as to formulate recommendations and actions that will improve health outcomes.

Future steps to improve data collection should involve building on the best practices of countries in the Americas. These steps should also involve further analysis of data collection issues that are specific to the inclusion of violence in the maternal mortality ratio.

One concern is that it may be difficult to confirm a woman's pregnancy status. This involves more than discussion and agreement among epidemiologists and health program managers about indicating pregnancy status on a death certificate or in a database (either by adding a box on a form or setting a code for a database). Forensic autopsy that includes the exploration of the uterine content has been useful in detecting early pregnancies (24), but this method is not widely available in many countries of the Americas.

A second data-collection issue is that it may be difficult to determine if domestic violence is the cause of death. There may be daunting ethical and safety concerns as well as challenges in ensuring the reliability of the information. Fearing social stigma or being afraid for their own safety, many persons who know about the events associated with the death of a pregnant woman may be unwilling to disclose that information. Whenever possible, courts, the police, and health institutions should work collaboratively on domestic violence research that takes a public health perspective. These kinds of partnerships have already proved successful in several cities in the United States (25). A "verbal autopsy" can be used outside of a medical facility to rebuild the events surrounding the death of a woman due to domestic violence $(23,26)$. This research technique consists of interviewing family members and/or acquaintances of the deceased woman in order to find out the medical causes of death and to ascertain the underlying personal, family, or community factors that may have contributed to the death.

For data processing there are some tools that are already available and others that are being developed. For instance, the categories and subcategories of the codes of the ICD-10 and the International Classification of External Causes of Injuries (ICECI) (2) help to characterize specific deaths due to injury. With the ICECI it is possible to identify the type of relationship between the victim and the perpetrator. Nevertheless, with both the ICD-10 and the ICECI it is impossible to identify all deaths of pregnant women, simply because pregnancy status is not coded (since pregnancy is obviously not a disease).

\section{FINAL CONSIDERATIONS}

The monitoring of maternal deaths due to domestic violence should be done through epidemiological surveillance systems. However, expanding and improving the systems so as to generate maternal mortality estimates that are accurate and that include deaths due specifically to domestic violence will require sustained political will, resources, and commitment to action. There are other approaches that can be useful for monitoring maternal deaths due to domestic violence, such as developing periodic ad hoc research. This approach could involve incorporating measurement of domestic violence into existing research or into future studies that use the Reproductive Age Mortality Study (RAMOS) methodology, which utilizes multiple sources of in- 
formation in investigating all deaths among women of childbearing age $(15,26)$. Furthermore, with the RAMOS methodology, the appropriateness of a definition of maternal death due to domestic violence can be tested, not only in the definition's conceptual aspects but also in its usefulness for data management processes and decision-making. Universal screening for domestic violence among pregnant women in both developed and developing countries could be another way to prospectively explore morbidity and mortality for women and newborns, as well as the appropriateness of certain interventions. Additional research could examine where the violence and/or death occurred, what the mechanism of injury was, and whether pregnancy was the motivation for the injury or murder.

It is not known if the current maternal mortality figures are concealing greater differences than are now indicated between developed countries and developing countries in the number of maternal deaths and in the number of such deaths caused by domestic violence. Obtaining information on maternal mortality due to domestic violence can help build understanding of the level of gender inequality that exists in countries. This information can also help ensure that the maternal mortality ratio accurately represents what it frequently is used as, that is, an indicator of various dimensions of social development. But more importantly, the information can help improve the capacities of health systems, help make it possible to achieve the Millennium Development Goal of reducing maternal mortality by $75 \%$ by 2015 , and help bring about greater gender equity.

In recent years both the World Health Organization (WHO) and the Pan American Health Organization (PAHO) have done an enormous amount to tackle the problem of domestic violence. An ongoing WHO multicountry study on the prevalence of domestic violence (27) will provide additional key information to better understand the health consequences that that violence has for women. PAHO research on domestic violence in Latin America and the Caribbean has been instrumental in setting intervention priorities, identifying the numerous individual and societal factors around domestic violence, and identifying the "critical path" that women who are victims of domestic violence follow as they seek help (28). PAHO is now conducting research to assess the extent of the relationship between domestic violence and maternal and perinatal health (29). Investing in research on this issue is essential to guiding and supporting countries in their efforts to review and improve their models of care intended to have healthy women, healthy families, and healthy communities existing within a framework of gender equality.

Acknowledgments. We would like to thank Elsa Gómez, Lilia Jara, Dinys Luciano, and Herland Tejerina, from the Pan American Health Organization, for their valuable comments. We also value our lively discussions with our colleagues Roberto Becker, John Silvi, and Patricia Ruiz. We would like to also thank Angela Bayer and Rachel Kaufman for their time in reviewing this paper. Henry Espinoza thanks Ana Langer, from the Population Council in Mexico, for motivating him to work in this research area.

\section{SINOPSIS}

\section{Muerte materna ocasionada por violencia doméstica: componente crítico e inadvertido de la mortalidad materna}

En este trabajo subrayamos la necesidad de contar las muertes maternas que ocurren como resultado de episodios de violencia doméstica, y también exponemos algunas de las principales dificultades que se enfrentan al tratar de hacerlo. Examinamos algunos elementos básicos que deben tenerse presentes al contar las muertes maternas de este tipo y explicamos cómo una definición de mortalidad materna que dé cabida a la violencia doméstica como causa de muerte mejorará la vigilancia epidemiológica y las intervenciones de salud. Lograr un acuerdo general acerca de la definición de "muerte materna por violencia doméstica" y un marco estratégico para responder a ese tipo de muerte constituiría un logro de gran importancia para los sectores de la comunidad internacional que velan por la salud de la mujer y la equidad de género.

Palabras clave: mujeres maltratadas, violencia doméstica, mortalidad materna, complicaciones del embarazo, vigilancia de la población, recolección de datos. 


\section{REFERENCES}

1. United Nations, Division for the Advancement of Women. Fourth World Conference on Women Beijing declaration [Internet site]. Available from http://www.un.org/womenwatch/ daw/beijing/platform/declar.htm Accessed 1 August 2004.

2. ICECI Coordination and Development Group. International classification of external causes of injuries (ICECI). Version 1.1a. Volume 1: tabular lists. Amsterdam, Consumer Safety Institute; Adelaide, AIHW National Injury Surveillance Unit; 2003.

3. World Health Organization. International statistical classification of diseases and related health problems, tenth revision. Geneva: WHO; 1993.

4. Ronsmans C, Khlat M. Adolescence and risk of violent death during pregnancy in Matlab, Bangladesh [letter]. Lancet. 1999:354(9188):1448.

5. McFarlane J, Campbell JC, Sharps P, Watson $\mathrm{K}$. Abuse during pregnancy and femicide: urgent implications for women's health. Obstet Gynecol. 2002;100(1):27-36.

6. Economic Commission for Latin America and the Caribbean. Eliminating gender-based violence, ensuring equality. ECLAC/UNIFEM regional assessment of actions to end violence against women in the Caribbean. Port-of-Spain: ECLAC; 2003.

7. Frautschi S, Cerulli A, Maine D. Suicide during pregnancy and its neglect as a component of maternal mortality. Int J Gynaecol Obstet. 1994;47(3):275-84

8. Rogo KO, Bohmer L, Ombaka C. Developing community-based strategies to decrease maternal morbidity and mortality due to unsafe abortion: preintervention report. East Afr Med J. 1999;76(11 Suppl):S1-71.

9. Campero L, Walker D, Hernández B, Espinoza $\mathrm{H}$, Reynoso S, Langer A. La contribución de la violencia a la mortalidad materna en el estado de Morelos. Salud Publica Mex. Forthcoming 2005.

10. United Nations. Declaration on the elimination of violence against women [In- ternet site]. Available from: http:// www.un.org/documents/ga/res/48/ a48r104.htm. Accessed 1 August 2004. (UN Resolution No. A/RES/48/104.)

11. Krug GE, Dahlberg LL, Mercy JA, Zwi $A B$, Lozano R, eds. World report on violence and health. Geneva: World Health Organization; 2002.

12. Ellsberg M, Heise L, Pena R, Agurto S, Winkvist A. Researching domestic violence against women: methodological and ethical considerations. Stud Fam Plann. 2001;32(1):1-16.

13. Gazmararian JA, Adams MM, Saltzman LE, Johnson $\mathrm{CH}$, Bruce FC, Marks JS, et al. The relationship between pregnancy intendedness and physical violence in mothers of newborns. The PRAMS Working Group. Obstet Gynecol. 1995;85(6):1031-8

14. Ganatra BR, Coyaji KJ, Rao VN. Too far, too little, too late: a community-based case-control study of maternal mortality in rural west Maharashtra, India. Bull World Health Organ. 1998;76(6):591-8.

15. Berg C, Danel I, Atrash H, Zane S, Bartlett L, eds. Strategies to reduce pregnancy-related deaths: from identification and review to action. Atlanta: Centers for Disease Control and Prevention; 2001.

16. World Health Organization. Reduction of maternal mortality: a joint WHO/ UNFPA/UNICEF/World Bank statement. Geneva: WHO; 1999.

17. Maine D, Rosenfield A. The AMDD program: history, focus and structure. Int J Gynaecol Obstet. 2001;74(2):99-104.

18. Dannenberg AL, Carter DM, Lawson HW, Ashton DM, Dorfman SF, Graham EH. Homicide and other injuries as causes of maternal death in New York City, 1987 through 1991. Am J Obstet Gynecol. 1995;172(5):1557-64

19. Petersen R, Gazmararian JA, Spitz AM, Rowley DL, Goodwin MM, Saltzman $\mathrm{LE}$, et al. Violence and adverse pregnancy outcomes: a review of the literature and directions for future research. Am J Prev Med. 1997;13(5):366-73.
20. Ballard TJ, Saltzman LE, Gazmararian JA, Spitz AM, Lazorick S, Marks JS. Violence during pregnancy: measurement issues. Am J Public Health. 1998;88(2): 274-6.

21. Watts C, Zimmerman C. Violence against women: global scope and magnitude. Lancet. 2002;359:1232-7.

22. AbouZahr C, Wardlaw T. Maternal mortality at the end of a decade: signs of progress? Bull World Health Organ. 2001;79(6):561-8.

23. World Health Organization. Beyond the numbers: reviewing maternal deaths and complications to make pregnancy safer. Geneva: WHO; 2004.

24. Krulewitch CJ, Pierre-Louis ML, de Leon-Gomez R, Guy R, Green R. Hidden from view: violent deaths among pregnant women in the District of Columbia, 1988-1996. J Midwifery Womens Health. 2001;46(1):4-10.

25. Block CR, McFarlane JM, Walker GR, Devitt CO. Beyond public records databases: field strategies for locating and interviewing proxy respondents in homicide research. Homicide Stud. 1999;3: 349-66.

26. Ronsmans C, Vanneste AM, Chakraborty J, Van Ginneken J. A comparison of three verbal autopsy methods to ascertain levels and causes of maternal deaths in Matlab, Bangladesh. Int J Epidemiol. 1998;27:660-6.

27. World Health Organization. The WHO multi-country study on women's health and domestic violence against women [Internet page]. Available from: http:// www.who.int/gender/violence/multicountry/en/. Accessed 1 August 2004.

28. Sagot M, Shrader E. La ruta crítica de las mujeres afectadas por la violencia intrafamiliar en América Latina: estudios de caso en diez países. Washington, D.C.: Organización Panamericana de la Salud; 2000.

29. Pan American Health Organization. Regional strategy for maternal mortality and morbidity reduction. Washington, D.C.: PAHO; 2002.

\section{The truths revealed by science are always greater than} the dreams it destroys.
[Las verdades que revela la ciencia siempre superan a los sueños que destruye.]

Emest Renan 